\title{
CDK4/6 inhibition protects normal cells against cancer therapy-induced damage
}

\author{
Ettickan Boopathi ${ }^{1}$, Chellappagounder Thangavel $^{2}$ \\ ${ }^{1}$ Department of Medicine, Center for Translational Medicine, ${ }^{2}$ Department of Radiation Oncology, Sidney Kimmel Medical College, Thomas \\ Jefferson University, Philadelphia, PA, USA \\ Correspondence to: Chellappagounder Thangavel, PhD. Department of Radiation Oncology, Sidney Kimmel Cancer Center, Department of Radiation \\ Oncology, Thomas Jefferson University, 233 South 10th St, BLSB 1028, Philadelphia, PA 19107, USA. Email: thangavel.chellappagounder@jefferson.edu; \\ Ettickan Boopathi, PhD. Department of Medicine, Center for Translational Medicine, Sidney Kimmel Medical College, Thomas Jefferson University, \\ Philadelphia, Pennsylvania, PA 19107, USA. Email: boopathi.ettickan@jefferson.edu. \\ Comment on: Weiss JM, Csoszi T, Maglakelidze M, et al. Myelopreservation with the CDK4/6 inhibitor trilaciclib in patients with small cell lung \\ cancer receiving 1st-line chemotherapy: a Phase 1b/randomized Phase 2 trial. Ann Oncol 2019;30:1613-21.
}

Submitted Nov 19, 2019. Accepted for publication Dec 26, 2019.

doi: $10.21037 /$ tcr.2019.12.86

View this article at: http://dx.doi.org/10.21037/tcr.2019.12.86

Multi-agent platinum and radiation regimens, the preferred treatment for advanced malignancy (1), have increased cancer survivor rates, but the higher doses that may be required to stop the cancer can be toxic to normal tissues (2-6). This cancer therapy induced non-target tissue toxicity is a major limitation in cancer treatment and normal tissue toxicity the "silent killer" of many cancer survivors. The toxicity appears during or post cancer therapy and leads to effects that range from subclinical dysfunction to irreversible organ failure or even death due to impaired vital organ function and its metabolism (Figure 1). The issue is a growing concern as the number of cancer survivors is projected to increase from 16.9 million in 2019 to 26.1 million by 2040 (7).

Current technologies are not efficient enough to detect early diagnostic markers for cancer therapy induced normal tissue toxicity (8). Furthermore, no FDA-approved cancer drugs or interventional or combination therapies provide both normal tissue protection and inhibit cancer growth. It is therefore clinically warranted to employ high throughput technologies to unmask and identify the cancer therapy induced gene signatures responsible for early and late normal tissue toxicity and to develop a novel therapeutic strategy to simultaneously protect normal tissue from cancer therapy induced toxicities and control cancer growth.

Large data including bioinformatic on clinical samples and other research documents have demonstrated that how chemo-radiation induces mitochondrial reactive oxygen species (ROS) (9) and promotes normal tissue DNA damage through oxidative stress (6). This damage in turn leads to deregulation of the tumor suppressor retinoblastoma tumor suppressor RB/E2F pathway $(10,11)$, which can result in DNA damage associated cancer progression, and ultimately to irreversible vital organ failure or death $(12,13)$. Cancer discoveries suggest that cancer cell proliferation and migration is tightly regulated by the tumor suppressor retinoblastoma gene (RB1) and its pathway. Retinoblastoma protein belongs to the pocket protein family which includes p07, p110 and p130, and the deregulated retinoblastoma protein pathway is observed in many tumor models. RB controls the excessive proliferation via transcriptional repression of $\mathrm{E} 2 \mathrm{~F}$ target genes at the $\mathrm{G} 1$ to $\mathrm{S}$ phase transition. Under pathological conditions retinoblastoma protein $\mathrm{pRb}$ is inactivated (hyperphosphorylated) by cyclin dependent kinases (CDK4/6), which are serine/threonine kinases. Tumor suppressor $\mathrm{pRb}$ harbors multiple serine residues and CyclinD/CDK4/6 complex phosphorylates $\mathrm{pRb}$ at serine residues, and hyper-phosphorylated $\mathrm{Rb}$ becomes inactive and fails to induce transcriptional repression on cell cycle gene promoters. Pfizer Global Research made a long-standing effort to discover a CDK4/6 inhibitor called palbociclib (PD 0332991) that selectively inhibits CDK4/6 activity and in a joint effort with Fry et al. successfully formulated and tested it on RB proficient 


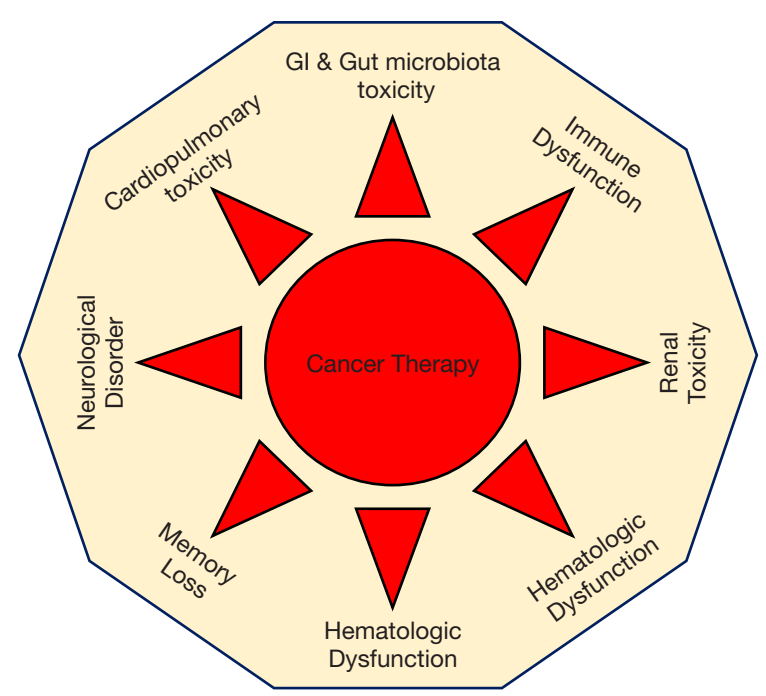

Figure 1 Cancer therapy induced toxicity on vital organs. Diagrammatic representation of cancer therapy induced cardiopulmonary toxicity, neurological disorder, memory loss, hematological dysfunction, bone fracture, renal toxicity, and immune dysfunction, gastrointestinal intestinal and gut microbiota toxicity in cancer patients.

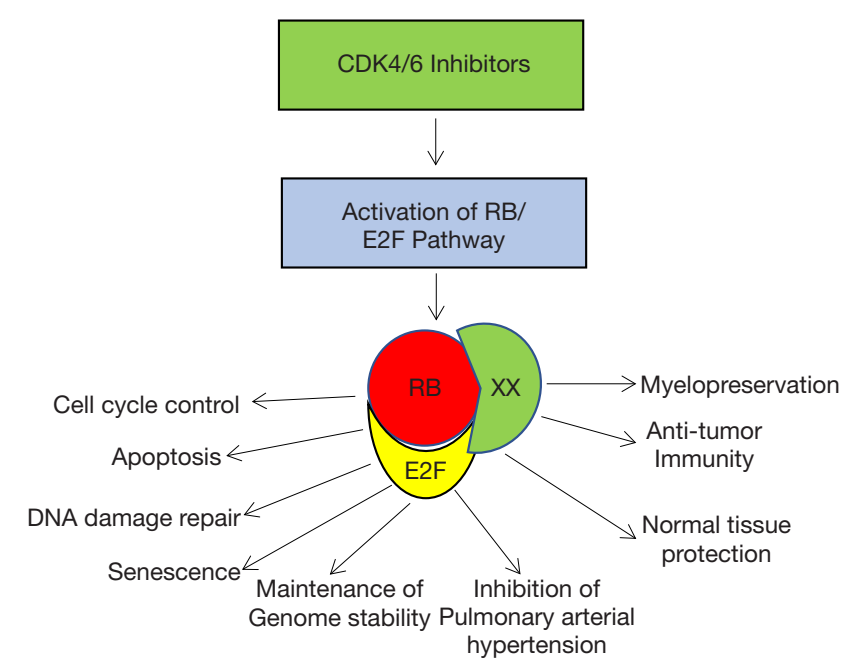

Figure 2 Tumor suppressive and normal tissue protective potential of CDK4/6 inhibitors. CDK4/6 inhibitors activate $\mathrm{RB} / \mathrm{E} 2 \mathrm{~F}$ signaling pathway and targets cell cycle machinery and induces apoptosis and cellular senescence. Additionally, CDK4/6 inhibitors involved maintaining genome stability by DNA repair mechanisms via RB dependent mechanism. CDK4/6 inhibition induces anti-tumor immunity and offers vital organ/cell protection, differentiation and myogenesis against cancer therapy induced toxicity. tumor models (14). The results from the study clearly demonstrated that palbociclib inhibited tumor growth in multiple tumor models in an RB proficient clinical setting.

Palbociclib functions as a potent antiproliferative agent in retinoblastoma protein $(\mathrm{pRb})$-positive tumor cells in vitro and in vivo and induces G1 arrest, with reduction in phospho-Ser780/Ser795 residues on $\mathrm{pRb}$ protein. Following the palbociclib discovery, additional CDK4/6 inhibitors were discovered: ribociclib, LEE 011, abemaciclib (LY2835219), and trilaciclib. Application of these CDK4/6 inhibitors on preclinical tumor models and use in clinical trials as single agent or fused with chemotherapy in patients with RB-positive tumors suggest that inhibition of CDK4/6 activity reestablishes cell cycle control by activating the $\mathrm{pRb}$ pathway. CDK4/6 inhibitors made to target ATP binding regions on CDK4/6 molecule. Palbociclib and ribociclib shows very high affinity to CDK4/6 protein and beyond cell cycle control and palbociclib also induces senescence and apoptosis via RB dependent mechanisms in RB positive cancer cells (15) as described in Figure 1.

The main purpose of this commentary on myelopreservation with CDK4/6 inhibitor trilaciclib by Weiss et al. (16) is to bring attention to the cancer research community that CDK4/6 inhibitors are not limited to suppression but also functions as novel protectors for normal cells against cancer therapy induced toxicity. Outcomes from multiples studies on CDK4/6 inhibitors also support the findings by Weiss et al. (16).

Mechanistic studies on an FDA-approved palbociclib (PD 0332991) anti-cancer drug have demonstrated in many tumor models that it targets the cell cycle and selectively inhibits cancer growth by activating the retinoblastoma tumor suppressor protein (inhibiting serine phosphorylation) and its signaling pathway $(15,17,18)$. Recent discovery on palbociclib suggests that palbociclib also functions as a novel protector of normal tissue against therapy induced toxicity via RB-dependent mechanisms $(15,19-21)$ and these studies also supports the work by Weiss et al. (16). CDK4/6 inhibition activates tumor suppressor protein $\mathrm{pRB}$ and the activated RB interacts with many of its interacting partners and performs multiple vital functions other than tumor suppression (Figure 2). In parallel, platinum-based cancer therapy induced damage on hematopoietic stem and progenitor cells (HSPC) causes multi-lineage myelosuppression. An intravenous application of trilaciclib (CDK4/6 inhibitor) (16) preserves HSPC and immune system function against chemotherapy (myelopreservation), and this discovery along 
with published documents together strongly supports that palbociclib triggers antitumor immunity as described in (21). Recent findings suggest that CDK4/6 inhibition triggers apoptosis in non-small cell lung cancer (15) via activation of the pRB pathway and that RB is localized to the nucleus (22) and involved in the DNA repair pathway via nonhomologous recombination process. These discoveries suggest that CDK4/6 inhibitors protect normal tissue from cancer therapy induced toxicity (19). Additionally, recent discoveries strongly suggest that the CDK4/6 inhibitors play a major role in controlling pulmonary hypertension (23) via the RB dependent pathway.

Cyclin-dependent kinase CDK4/6 plays a vital role in mammalian cell cycle regulation and it drives progression of cells into $S$ phase (DNA synthesis phase) of cell division. In tumors, CDK4/6 activity deregulates the $\mathrm{p} 16^{\mathrm{INK} 4 \mathrm{a}}-\mathrm{Rb}$ pathway that leads to uncontrolled cell division and cancer cell proliferation. Retinoblastoma tumor suppressor protein interacts with hundreds of molecules, involves in DNA repair pathway, and maintains genome integrity. Recently, reversible CDK4/6 inhibitors (palbociclib and trilaciclib) were employed to protect the immune system from chemotherapy induced toxicity. Weiss et al. (16) showed chemotherapy tolerance in lung cancer patients with myelopreservation benefits. Similarly, pulmonary arterial hypertension is mediated via proliferation of pulmonary arterial smooth muscle cells (PASMCs) with high CDK4/6 activity and poor prognosis. Selective inhibition of CDK4/6 via palbociclib inhibits PASMC proliferation via RB/E2F pathway (23).

Recent preclinical studies on CDK4/6 inhibitors suggest that CDK4/6 inhibitors play a vital role in normal cell protection other than tumor suppression. Additionally, CDK4/6 inhibition in human subjects by Weiss et al. reflects that CDK4/6 inhibitors have defensive potential to fight against cancer and therapy induced toxicity, and also triggers anti-tumor immunity in preclinical models (16,21,23-25). All of these studies suggest that CDK4/6 specific inhibition offers normal tissue protection and supports the Weiss et al. discovery with regard to myelopreservation in lung cancer patients (16). Taken together, these studies suggest that CDK4/6 inhibitors control cancer cell growth and simultaneously provide normal tissue protection against cancer therapy induced toxicities. Further studies are warranted to define the mechanistic pathways involved in normal tissue protection with CDK4/6 inhibition and to further interrogate whether this reversible CDK4/6 inhibition causes any long term side effects. Additionally, it is important to apply high throughput RNA and DNA sequencing technologies to investigate whether CDK4/6 inhibition promotes any drug resistance or any irreversible phenotypic or genotypic changes in normal tissue.

\section{Acknowledgments}

Funding: The study was funded by the US National Institute of Health (NIH) National Institute of Diabetes and Digestive and Kidney Diseases (R01 grant DK100483 to E Boopathi.

\section{Footnote}

Provenance and Peer Review: This article was commissioned and reviewed the Section Editor Dr. Wei Xu (Division of Respiratory Disease, Department of Geriatrics, the First Affiliated Hospital of Nanjing Medical University, Nanjing, China).

Conflicts of Interest: Both authors have completed the ICMJE uniform disclosure form (available at http://dx.doi. org/10.21037/tcr.2019.12.86). The authors have no conflicts of interest to declare. The authors have no conflicts of interest to declare.

Ethical Statement: The authors are accountable for all aspects of the work in ensuring that questions related to the accuracy or integrity of any part of the work are appropriately investigated and resolved.

Open Access Statement: This is an Open Access article distributed in accordance with the Creative Commons Attribution-NonCommercial-NoDerivs 4.0 International License (CC BY-NC-ND 4.0), which permits the noncommercial replication and distribution of the article with the strict proviso that no changes or edits are made and the original work is properly cited (including links to both the formal publication through the relevant DOI and the license). See: https://creativecommons.org/licenses/by-nc-nd/4.0/.

\section{References}

1. Voorwerk L, Slagter M, Horlings HM, et al. Immune induction strategies in metastatic triple-negative breast cancer to enhance the sensitivity to PD-1 blockade: the TONIC trial. Nat Med 2019;25:920-8.

2. Darby SC, Ewertz M, McGale P, et al. Risk of ischemic heart disease in women after radiotherapy for breast 
cancer. N Engl J Med 2013;368:987-98.

3. Dugbartey GJ, Peppone LJ, de Graaf IA. An integrative view of cisplatin-induced renal and cardiac toxicities: Molecular mechanisms, current treatment challenges and potential protective measures. Toxicology 2016;371:58-66.

4. Giordano SH, Kuo YF, Freeman JL, et al. Risk of cardiac death after adjuvant radiotherapy for breast cancer. J Natl Cancer Inst 2005;97:419-24.

5. Spallarossa P, Tini G, Sarocchi M, et al. Identification and Management of Immune Checkpoint InhibitorRelated Myocarditis: Use Troponin Wisely. J Clin Oncol 2019;37:2201-5.

6. Morigi M, Perico L, Rota C, et al. Sirtuin 3-dependent mitochondrial dynamic improvements protect against acute kidney injury. J Clin Invest 2015;125:715-26.

7. Bluethmann SM, Mariotto AB, Rowland JH. Anticipating the "Silver Tsunami": Prevalence Trajectories and Comorbidity Burden among Older Cancer Survivors in the United States. Cancer Epidemiol Biomarkers Prev 2016;25:1029-36.

8. Florescu M, Cinteza M, Vinereanu D. Chemotherapyinduced Cardiotoxicity. Maedica (Buchar) 2013;8:59-67.

9. Yang H, Villani RM, Wang H, et al. The role of cellular reactive oxygen species in cancer chemotherapy. J Exp Clin Cancer Res 2018;37:266.

10. Fujiu K, Nagai R. Fibroblast-mediated pathways in cardiac hypertrophy. J Mol Cell Cardiol 2014;70:64-73.

11. Alam P, Haile B, Arif M, et al. Inhibition of SenescenceAssociated Genes Rb1 and Meis2 in Adult Cardiomyocytes Results in Cell Cycle Reentry and Cardiac Repair PostMyocardial Infarction. J Am Heart Assoc 2019;8:e012089.

12. Thangavel C, Boopathi E, Ciment S, et al. The retinoblastoma tumor suppressor modulates DNA repair and radioresponsiveness. Clin Cancer Res 2014;20:5468-82.

13. Marshall AE, Roes MV, Passos DT, et al. RB1 Deletion in Retinoblastoma Protein Pathway-Disrupted Cells Results in DNA Damage and Cancer Progression. Mol Cell Biol 2019. doi: 10.1128/MCB.00105-19.

14. Fry DW, Harvey PJ, Keller PR, et al. Specific inhibition of cyclin-dependent kinase 4/6 by PD 0332991 and associated antitumor activity in human tumor xenografts. Mol Cancer Ther 2004;3:1427-38.

15. Thangavel C, Boopathi E, Liu Y, et al. Therapeutic Challenge with a CDK 4/6 Inhibitor Induces an RBDependent SMAC-Mediated Apoptotic Response in NonSmall Cell Lung Cancer. Clin Cancer Res 2018;24:1402-14.

16. Weiss JM, Csoszi T, Maglakelidze M, et al. Myelopreservation with the CDK4/6 inhibitor trilaciclib in patients with small cell lung cancer receiving 1st-line chemotherapy: a Phase 1b/randomized Phase 2 trial. Ann Oncol 2019;30:1613-21.

17. Raphael J, Helou J, Pritchard KI, et al. Palbociclib in hormone receptor positive advanced breast cancer: A costutility analysis. Eur J Cancer 2017;85:146-54.

18. Vijayaraghavan S, Karakas C, Doostan I, et al. CDK4/6 and autophagy inhibitors synergistically induce senescence in $\mathrm{Rb}$ positive cytoplasmic cyclin E negative cancers. Nat Commun 2017;8:15916.

19. Wei L, Leibowitz BJ, Wang X, et al. Inhibition of CDK4/6 protects against radiation-induced intestinal injury in mice. J Clin Invest 2016;126:4076-87.

20. Cook R, Zoumpoulidou G, Luczynski MT, et al. Direct involvement of retinoblastoma family proteins in DNA repair by non-homologous end-joining. Cell Rep 2015;10:2006-18.

21. Goel S, DeCristo MJ, Watt AC, et al. CDK4/6 inhibition triggers anti-tumour immunity. Nature 2017;548:471-5.

22. Velez-Cruz R, Manickavinayaham S, Biswas AK, et al. RB localizes to DNA double-strand breaks and promotes DNA end resection and homologous recombination through the recruitment of BRG1. Genes Dev 2016;30:2500-12.

23. Weiss A, Neubauer MC, Yerabolu D, et al. Targeting cyclin-dependent kinases for the treatment of pulmonary arterial hypertension. Nat Commun 2019;10:2204.

24. Deng J, Wang ES, Jenkins RW, et al. CDK4/6 Inhibition Augments Antitumor Immunity by Enhancing T-cell Activation. Cancer Discov 2018;8:216-33.

25. Zhang J, Bu X, Wang H, et al. Cyclin D-CDK4 kinase destabilizes PD-L1 via cullin 3-SPOP to control cancer immune surveillance. Nature 2018;553:91-5.
Cite this article as: Boopathi E, Thangavel C. CDK4/6 inhibition protects normal cells against cancer therapy-induced damage. Transl Cancer Res 2020;9(2):405-408. doi: 10.21037/ tcr.2019.12.86 